\title{
Evaluation of two sweeping methods for estimating the number of immature Aedes aegypti (Diptera: Culicidae) in large containers
}

\author{
Margareth Regina Dibo ${ }^{[1],[2]}$, Eliane Aparecida Fávaro ${ }^{[2]}$, Maisa Carla Pereira Parra ${ }^{[2]}$ \\ Thiciane Cristian dos Santos ${ }^{[1]}$, Juliana Haines Cassiano ${ }^{[2]}$, Keli Vanessa de Souza Deitz ${ }^{[2]}$, \\ Aline Michelle dos Santos Pagliotto ${ }^{[1]}$, Nathália Zini ${ }^{[1]}$, Daniela Regina Benetti ${ }^{[2]}$ \\ and Francisco Chiaravalloti-Neto ${ }^{[3]}$
}

[1]. Superintendência de Controle de Endemias, Governo do Estado de São Paulo, São José do Rio Preto, SP. [2]. Departamento de Epidemiologia e Saúde Coletiva, Faculdade de Medicina de São José do Rio Preto, São José do Rio Preto, SP. [3]. Departamento de Epidemiologia, Faculdade de Saúde Pública, Universidade de São Paulo, São Paulo, SP.

\begin{abstract}
Introduction: Here, we evaluated sweeping methods used to estimate the number of immature Aedes aegypti in large containers. Methods: III/IV instars and pupae at a 9:1 ratio were placed in three types of containers with, each one with three different water levels. Two sweeping methods were tested: water-surface sweeping and five-sweep netting. The data were analyzed using linear regression. Results: The five-sweep netting technique was more suitable for drums and water-tanks, while the water-surface sweeping method provided the best results for swimming pools. Conclusions: Both sweeping methods are useful tools in epidemiological surveillance programs for the control of Aedes aegypti.
\end{abstract}

Keywords: Aedes aegypti. Sweeping. Entomological surveillance.

The quantification of Aedes aegypti larvae and pupae is practical in small- and medium-sized containers but becomes difficult in large ones. Sampling large containers is laborintensive and time-consuming, and it is also considered to be privacy-invasive by household residents ${ }^{1}$. Several authors ${ }^{1-4}$ have proposed alternative techniques, such as sweep-net or sweeping methods, to estimate the number of immature A. aegypti in large water-storage containers.

Based on studies of this technique, Tun-Lin et al. ${ }^{4}$, RomeroVivas et al. ${ }^{3}$ and Romero et al. ${ }^{5}$ reported that a single sweep around the container at the water's surface (the water-surface sweeping method) is sufficient for estimating the number of larvae and pupae present, while other authors have suggested that the method is more effective when performed in a swirling motion. Kubota et al. ${ }^{1}$ proposed eight sequential sweeps to estimate the number of stage IV instars. Knox et al. ${ }^{2}$ argued that a five-sweep technique around the entire container (the fivesweep netting technique) is able to estimate the total number of immatures. The objective of this study was to conduct laboratory evaluations of two methods used to estimate the amount of immature $A$. aegypti in large water-storage containers, watersurface sweeping and five-sweep netting.

\footnotetext{
Address to: Dr. Francisco Chiaravalloti Neto. Dept ${ }^{0}$ de Epidemiologia/FSP/ USP. Av. Dr. Arnaldo 715, 01246-904 São Paulo, SP, Brasil.

Phone: 5511 3061-7920

e-mail: franciscochiara@usp.br

Received 31 October 2011

Accepted 13 January 2012
}

São José do Rio Preto is located in northwestern São Paulo (2049'11'S and 49'22'46”W), Brazil, 498m above sea level, with a population of 408,258 . The climate is tropical, with an average annual temperature of $25^{\circ} \mathrm{C}$ and an annual precipitation of approximately $1,200 \mathrm{~mm}$.

The presence of $A$. aegypti in the city was detected by a survey performed in 1985, and the first autochthonous cases of dengue were recorded in 1990 together with the introduction of the serotype 1 dengue virus (DEN 1) virus. The disease is considered to be endemic to the $\operatorname{city}^{6}$, and four viral serotypes are currently in circulation.

Immature $A$. aegypt $i$ were obtained by placing oviposition traps at pre-selected sites in São José do Rio Preto. Straws were removed from the traps and taken to the laboratory for drying, counting and storing of the eggs. Next, the eggs were submerged in plastic trays for hatching. The larvae were fed with fish feed until stage III/IV instars and pupae appeared, which were subsequently used for experimentation.

The experiments were conducted in three stages: the first stage, performed in November 2008, included only A. aegypti pupae; the second stage, performed in June/July 2009, included III/IV instars and pupae; the third stage, performed in July/ August 2010, also included III/IV instars and pupae. The sweeps were performed using a fine white-mesh net $(15 \mathrm{~cm}$ in diameter and $20 \mathrm{~cm}$ in length) with a $1.5 \mathrm{~m}$ handle. The watersurface sweeping method, consisting of a single sweep around the periphery of the container at the water's surface, was used in stages 1 and $2^{3,4}$. The five-sweep netting method, as described by Knox et al. ${ }^{2}$, was used in stage 3 . 
The water-surface sweeping method was performed at three water levels $(1 / 3,2 / 3$ and $3 / 3)$ in three large water-storage containers: a 200 liters plastic drum, a 500 liters round polyethylene water-tank and a 1,000 liters swimming pool. The five-sweep netting method was performed in drums and water-tanks. A 15 -sweep experiment was conducted for each container type and water level.

In stage 1, each experiment involved introducing 70 pupae into each container for the first five sweeps, 140 pupae for the next five sweeps and 210 pupae for the last five sweeps. In stages 2 and 3, A. aegypti III/IV instars and pupae were placed in containers at a 9:1 larvae:pupae ratio at three different numbers of immatures $(60,160$ and 320$)$, with five sweeps per quantity.

Five minute intervals were observed between sweeps. The duration of each sweep was timed, and the water temperature was measured. All III/IV instars and pupae sampled from each sweep were counted, and dead or damaged immatures Aedes aegypti were replaced.

The experimental data were recorded in spreadsheets, and simple linear regression analyses were used to calculate calibration factors $(\mathrm{CFs})^{7}$, indexes that, when multiplied by the number of immature Aedes aegypti collected by sweeping, allow estimation of the number of immature A. aegypti in each container type and volume ${ }^{3}$.

For linear regression analysis, the number of immature $A$. aegypti collected by sweeping was considered as the dependent variable, the number of immature $A$. aegypti residing in the container was considered as the independent variable, and the intercept was set equal to zero (the inexistence of immature forms harboring the container corresponded to zero immature forms collected by sweeping). The outcomes of these analyses were the linear regression coefficients, the values of the coefficients of determination $\left(\mathrm{r}^{2}\right)$ that were used to compare the calibration factors derived in the three stages of the study and the p-values of the models (F-test). The CF values corresponded to the inverse of the regression coefficient values. Mean water temperature and sweeping duration ( \pm standard deviation) were measured in each experiment.

The CFs derived for larvae and pupae are shown in Figure 1, with respective 95\% confidence intervals for each stage, container type and volume. Regression analysis models for all experiments were significant, with $\mathrm{p}$-values less than 0.003 (F-test). The CFs derived for larvae were higher than those for pupae, indicating that a higher percentage of pupae were collected in all experiments compared to larvae. The mean water temperature $\left({ }^{\circ} \mathrm{C}\right.$ ) and sweeping duration (s) for each experiment are shown in Table 1. Generally, the mean water temperature showed little variability across the three study stages. The mean sweeping durations ranged from 19 to $47 \mathrm{~s}$ and were lower for the drum and water-tank and higher for the swimming pool. The mean sweeping duration was higher in stage 3 compared to stages 1 and 2 .

The coefficients of determination $\left(\mathrm{r}^{2}\right)$ from the linear regression analyses used to derive the CFs estimating the number of larvae and pupae are shown in Table 2. In stages 2 and 3, all coefficients of determination were higher for pupae compared
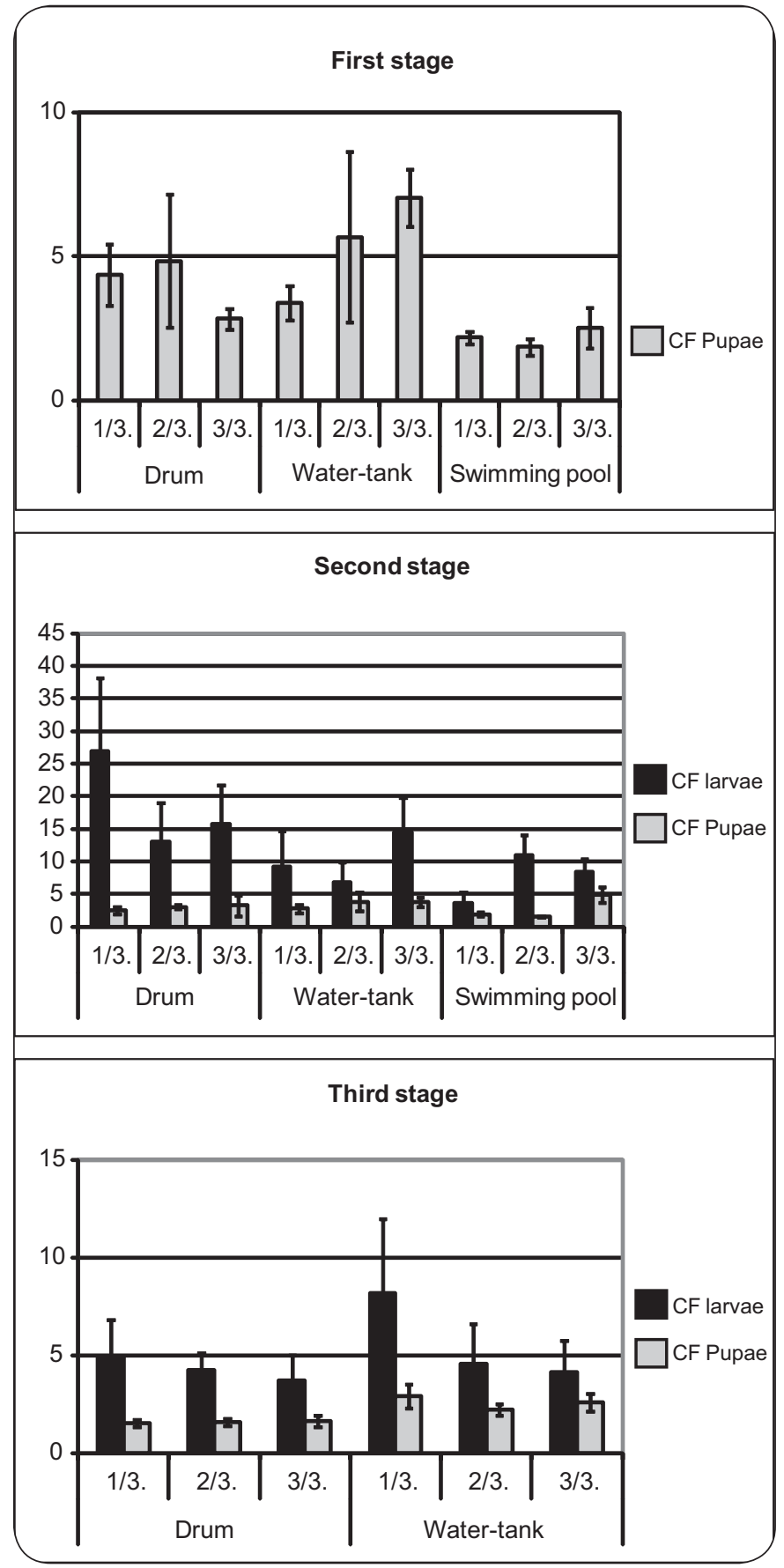

FIGURE 1 - Calibration factors (CFs) with 95\% confidence intervals for Aedes aegypti pupae (stage 1 of the experiment) and III/IV instars and pupae (stages 2 and 3) in large water-storage containers. Stages 1 and 2: water-surface sweeping method; stage 3: five-sweep netting technique.

to larvae, except in two cases. In stage 3, all coefficients of determination for larvae and pupae were equal to or higher than those observed in stage 2, except in one case. Moreover, the coefficients of determination for pupae in stage 3 exhibited less variation than those in stages 1 and 2.

In routine epidemiological surveys, especially surveys designed to calculate the productivity of $A$. aegypti larvae and pupae, total immature counts are impractical in large waterstorage containers because they are time-consuming and 
TABLE 1 - Sweeping duration (s) and water temperature $\left({ }^{\circ} \mathrm{C}\right)$ with respective standard deviations, according to study stage, container type and water level.

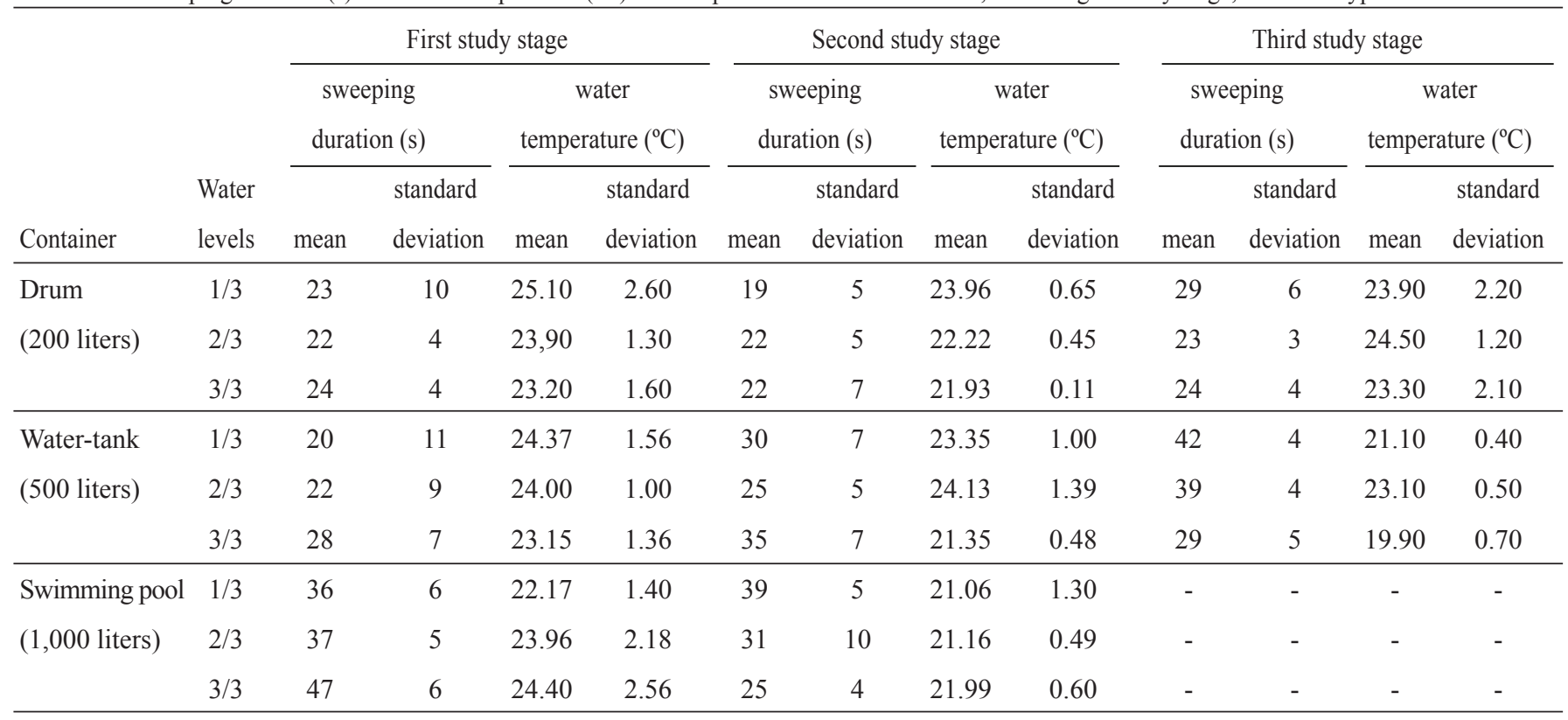

s: seconds.

TABLE 2 - Coefficient of determination $\left(\mathrm{r}^{2}\right)$ values from linear regression analyses used to estimate calibration factors for Aedes aegypti larvae and pupae according to study stage, container type and water level.

\begin{tabular}{|c|c|c|c|c|c|c|}
\hline \multirow[b]{3}{*}{ Container } & \multirow[b]{3}{*}{ Water level } & \multicolumn{5}{|c|}{ Study stage } \\
\hline & & \multirow{2}{*}{$\frac{\mathrm{I}}{\text { pupae }}$} & \multicolumn{2}{|c|}{ II } & \multicolumn{2}{|c|}{ III } \\
\hline & & & larvae & pupae & larvae & pupae \\
\hline Drum & $1 / 3$ & 0.84 & 0.65 & 0.87 & 0.70 & 0.96 \\
\hline \multirow[t]{2}{*}{ (200 liters) } & $2 / 3$ & 0.59 & 0.61 & 0.96 & 0.89 & 0.96 \\
\hline & $3 / 3$ & 0.95 & 0.69 & 0.57 & 0.72 & 0.91 \\
\hline Water-tank & $1 / 3$ & 0.91 & 0.48 & 0.87 & 0.60 & 0.88 \\
\hline \multirow[t]{2}{*}{ (500 liters) } & $2 / 3$ & 0.55 & 0.59 & 0.69 & 0.63 & 0.95 \\
\hline & $3 / 3$ & 0.94 & 0.70 & 0.91 & 0.68 & 0.92 \\
\hline Swimming poll & $1 / 3$ & 0.97 & 0.60 & 0.91 & - & - \\
\hline \multirow[t]{2}{*}{ (1,000 liters) } & $2 / 3$ & 0.93 & 0.80 & 0.98 & - & - \\
\hline & $3 / 3$ & 0.81 & 0.84 & 0.84 & - & - \\
\hline
\end{tabular}

sometimes require the disposal of the accumulated water ${ }^{8}$. In this study, the use of the sweeping method coupled to a $\mathrm{CF}^{3}$ was found to be a viable alternative for use in entomological surveys. This technique allows for a rapid estimation of the number of immatures in large water-storage containers without disposal of the water in the container. In this study, the average time for the entire procedure was always less than one minute, even for the five-sweep netting technique in water drums and tanks and for the water-surface sweeping performed in swimming pools.

In a study conducted in Fortaleza, Martins et al. ${ }^{9}$ verified that water drums and tanks corresponded to $11.8 \%$ and $9.8 \%$ of the total containers that could harbour immature $A$. aegypti, respectively. Water drums and tanks are still used for water storage in São José do Rio Preto (SUCEN: unpublished data), even though virtually all households in the city have adequate tap water and sanitation systems ${ }^{10}$. When confronted by entomological surveillance technicians, household residents strongly oppose the disposal of the water accumulated in these large containers for immature counting. Therefore, larger waterstorage containers should be surveyed with the five-sweep netting technique, given the superior results obtained with this method as compared to the water-surface sweeping method ${ }^{2}$.

The superior results obtained with the five-sweep netting method are due to the accumulation of immatures in the center 
of the water column after swirling, facilitating their collection with the net. However, this method is not viable for large containers with greater storage capacity. For such containers, water-surface ${ }^{3,4}$ sweeping should be used in a similar manner as for the case of swimming pools without adequate treatment in the City of São José do Rio Preto.

Tun-Lin et al. ${ }^{4}$ observed that temperature affects the vertical distribution of larvae in the water column and their recovery during sweeping; therefore, temperature should be considered when estimating immature numbers. In this study, there was little variation in water temperature because of the tropical climate, and thus, temperature was not taken into account when deriving the calibration factors.

Focks et al. ${ }^{11}$ argued that entomological measures used in A. aegypti control programs for quantifying vector infestation are inefficient because they are not directly associated with the risk of dengue transmission. Authors such as Gomes et al. ${ }^{12}$ have sought other methods to obtain entomological measurements, such as the use of Adultrap traps for the collection of female A. aegypti; using these methods, the quantity collected could be related to the transmission of dengue. Focks ${ }^{8}$ proposed the quantification of pupae as an alternative measure given their low mortality rates and direct relationship with the number of adult mosquitoes. To search for better indicators of dengue risk, Tun-Lin et al. ${ }^{13}$ investigated the productivity of immature $A$. aegypti and their use for surveillance of the vector. According to Romero et al. ${ }^{5}$, sweeping is an accurate method for estimating the number of immatures in large waterstorage containers, a result that is supported by data from this study. Thus, the sweeping method can be used in entomological surveillance programs to assess intervention methods and evaluate the risk of dengue virus transmission.

The water-surface and five-sweep netting methods for estimating numbers of larvae and pupae can be easily implemented in entomological surveys of $A$. aegypti through appropriate training programs for technicians working in the field of vector control. Nevertheless, the effect of water temperature on the recovery rates of larvae and pupae ${ }^{4}$, as well as its possible influence on CF values, should be taken into account when applying this method in localities with climates that differ from that of São José do Rio Preto. When adapting this method to situations other than those considered here, another relevant issue is the material used for the construction of the container.

\section{CONFLICT OF INTEREST}

The authors declare that there is no conflict of interest.

\section{FINANCIAL SUPPORT}

This study was funded by Fundação de Amparo à Pesquisa do Estado de São Paulo (FAPESP; Foundation for Research Support of São Paulo) - Process 2008/03799-1.

\section{REFERENCES}

1. Kubota R, Brito M, Voltolini JC. Método de varredura para exame de criadouros de vetores de dengue e febre amarela urbana. Rev Saude Publica 2003; 37 : 263-265.

2. Knox BT, Yen TY, Nam SV, Gatton LM, Kay HB, Ryan AP. Critical Evaluation of Quantitative Sampling Methods for Aedes aegypti (Diptera: Culicidae) Immatures in Water Storage Containers in Vietnam. J Med Entomol 2007; 44:192-204.

3. Romero-Vivas CME, Llinás H, Falconar AKI. Three calibration factors, applied to a rapid sweeping method, can accurately estimate Aedes aegypti (Diptera: Culicidae) pupal numbers in large water-storage containers at all temperatures at which dengue virus transmission occurs. J Med Entomol 2007; 44:930-937.

4. Tun-Lin W, Kay BH, Burkot TR. Quantitative sampling of immature Aedes aegypti in metal drums using sweep net and dipping methods. J Am Mosq Control Assoc 1994; 10:390-396.

5. Romero CME, Llinás H, Falconar AKI. Evaluation of rapid water-surface sweeping method to accurately estimate numbers of Aedes aegypti (Diptera: Culicidae) late larval stages in large water-storage containers: comparison with pupal estimates. Biomedica 2010; 30:268-275.

6. Mondini A, Chiaravalloti-Neto F, Sanches MGY, Lopes JCC. Análise espacial da transmissão de dengue em cidade de porte médio do interior paulista. Rev Saude Publica 2005; 39:444-451.

7. Altman DG. Practical Statistics for Medical Research. Boca Raton: Chapman \& Hall/CRC; 1999.

8. Focks DA. A review of entomological sampling methods and indicators for dengue vectors. Flórida, World Health Organization, 2003.

9. Martins VEP, Alencar CHM, Facó PEG, Dutra RF, Alves CR, Pontes RJS, et al. Distribuição espacial e características dos criadouros de Aedes albopictus e Aedes aegypti em Fortaleza, Estado do Ceará. Rev Soc Bras Med Trop 2010; 43:73-77.

10. Prefeitura Municipal de São José do Rio Preto. Conjuntura Econômica [Internet]. São José do Rio Preto: Prefeitura Municipal [Cited 2011 October 19]. Available from: http://www.riopreto.sp.gov.br/PortalGOV/ do/subportais_Show?c=146/.

11. Focks DA, Brenner RJ, Hayes J, Daniels E. Transmission Thresholds for dengue in terms of Aedes aegypti pupae per person with discussion of their utility in source reduction efforts. Am J Trop Med Hyg 2000; 62: 11-18.

12. Gomes AC, Silva NN, Bernal RTI, Leandro AS, Camargo NJ, Silva AM, et al. Especificidade da armadilha Adultrap para capturar fêmeas de Aedes aegypti (Diptera: Culicidae). Rev Soc Bras Med Trop 2007; 40:216-219.

13. Tun-Lin W, Kay BH, Barnes A. Understanding productivity, a key to Aedes aegypti surveillance. Am J Trop Med Hyg 1995; 53:595-601. 